\title{
Genomik auf Rosenholz
}

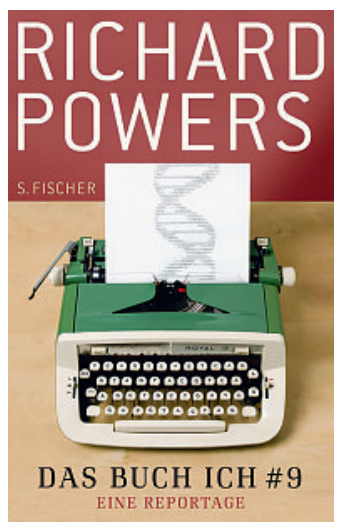

1 Powers R. Das Buch Ich Eine Reportage. Frankfurt a. M.: S. Fischer Verlag; 2010.
Nach einer unruhigen Wartezeit von vier Monaten, 2000 Arbeitsstunden und 9000 Stunden Rechnerzeit erhielt der amerikanische Romancier Richard Powers den teuer bezahlten USB-Stick mit seinen sechs Milliarden gespeicherten Basenpaaren ACTG. Natürlich in einem Kästchen aus Rosenholz, wie es sich gehört, wenn man als Nummer neun seinen vollständigen genetischen Bauplan kennt.

Das grosse Geschäft der Biotech-Industrie steht erst am Anfang. Noch ist das individuelle Genom ein Luxusgut für Hollywoodgrössen und HedgefondsManager, doch die Preise werden massiv sinken, so der Schriftsteller, dessen Bericht erstmals 2008 in der Zeitschrift «Gentlemen's Quarterly» veröffentlicht wurde und jetzt als Buch vorliegt [1]. Powers schildert anschaulich den Weg von der Information im Forschungszentrum der Harvard Medical School zur Blutentnahme in Boston, zur Isolation und Reinigung der DNS in New Jersey und der Sequenzierung in China, bis zur grafischen Darstellung und Interpretation der Chromosomen auf seinem Computer. Obwohl die Farbcodierung 248 genetische Varianten aufweist, die ein erhöhtes Risiko für rund 77 Krankheiten bedeuten, kann er sich vorläufig beruhigt zurücklehnen. Noch genüge der hausärztliche Rat: gesünder essen, mehr bewegen, entspannt leben, wach und neugierig bleiben, nur dass diese Erkenntnis auf Molekülebene eine neue Autorität erhalte.

\section{«Doch ein immer grösseres Wissen erweist sich auch als immer kür- zere Leine»}

So einfach dürfte es in naher Zukunft nicht mehr sein, denn wöchentlich werden neue Entdeckungen und Therapien publiziert, etwa von ADHS-Genabschnitten auf dem Chromosom 16, das die Hirnentwicklung beeinflusst, von Therapien einer Thalassaemia major oder der gezielten Genblockade bei Tumoren mittels eines komplexen Verfahrens wie die Ribonukleinsäure-Interferenz. Allein 2007 wurden die genetischen Grundlagen von einem neuen Dutzend verschiedener Krankheiten entdeckt. Die Reportage bietet eine interessante Momentaufnahme der aktuellen Anstrengungen auf dem Gebiet der Individualgenomik, welche die heutige Medizin völlig verändern dürfte. Von führenden Experten als genomische Revolution bezeichnet, werden die gesellschaftlichen Folgen mit der Einführung der Personal- computer Ende der 1970er Jahre verglichen. Neue Märkte würden folgen, riesige Kapitalsummen stehen bereit. Powers: «Die Gen-Generation ist da, und alles, was die menschliche Phantasie und der menschliche Irrsinn hervorbringen können, die Genialität und die Quacksalberei, stürmt auf uns ein.» Der Autor teilt nicht blindlings den Enthusiasmus seiner Berater, er äussert bei aller Neugier auch grundsätzliche Bedenken: «Es heisst ja, die Wahrheit solle uns befreien. Doch ein immer grösseres Wissen erweist sich auch als immer kürzere Leine.» Nun hat sich der flüchtige Augenblick schon zum nächsten weiterentwickelt, bevor man ihn zu fassen bekommt. Das Tempo der Forschung und ihrer Anwendungen überfordert Gesetzgeber und Ethiker, mögen Letztere fundamental, narrativ oder wie auch immer argumentieren. Dennoch überwiegen beim stolzen Besitzer der genetischen Kristallkugel die positiven Einschätzungen. Sein Optimismus malt unbeirrt die goldenen Verheissungen. Denn die gezielte Steuerung soll den Zufall ersetzen. «Es gab einmal eine Zeit, da bekamen wir unsere Karten vom Schicksal zugeteilt, von Gott oder einem unzuverlässigen Erzähler. Das Leben bestand darin, dass wir das Beste aus unserem Blatt zu machen versuchten. Heute kann man die Karten neu verteilen.» Unglück und Tod, das war einmal, bald ist jeder seines Glückes Schmied. Das nennt sich dann «partizipative Medizin». Dabei geht es um Kontrolle, um Zugriff zwecks Autonomie und Selbstbestimmung, um das ganze Programm der Moderne mit dem absoluten Vorrang der Naturwissenschaften. Können wir mit dem angekündigten Risikomanagement das Glück erzwingen oder sind wir nur daran, uns eine neue Zwangsjacke zu verpassen?

Die Technologiegläubigkeit ist in den USA grösser als in Europa, wo Parlamente gentechnikfreie Zonen diskutieren und der Bundesrat das ablaufende Moratorium für gentechnisch veränderte Pflanzen und Tiere zur Produktion von Lebensmitteln bis 2013 verlängern will. Im Land der unbegrenzten Möglichkeiten lehnt ein Drittel die Evolutionstheorie ab und etwa gleich viele glauben an die Existenz von UFOs. So viel zum rationalen Subjekt der Aufklärung. Gemäss Nietzsche ist der Mensch «das noch nicht festgelegte Tier», oder mit den Worten Powers: «Der Code ist veränderlich und ist es von jeher gewesen. $\mathrm{Ob}$ es nun gut ist oder nicht - unser Geist hat sich noch nie in eine Flasche bannen lassen.» Im real existierenden Wissenschaftsbetrieb stecken auch sehr viel Ideologie und sehr viel Markt. Allein schon darum lohnt es sich, den gut verständlichen, kurzen Bericht des Autors zu lesen und darüber hinauszudenken.

Erhard Taverna 